\title{
A COMPACT, RF-DRIVEN, PULSED ION SOURCE FOR INTENSE NEUTRON GENERATION*
}

\author{
L. T. Perkins, C. M. Celata, K. N. Leung, D. S. Pickard, R. Vilaithong, and M. D. Williams \\ Lawrence Berkeley National Laboratory, Berkeley, CA 94720 USA
}

\begin{abstract}
Lawrence Berkeley National Laboratory is currently developing a compact, sealed-accelerator-tube neutron generator for activation analysis applications. This portable generator is projected to produce a neutron flux in the range of $10^{9}$ to $10^{10} \mathrm{D}-\mathrm{T}$ neutrons per second. A 2 $\mathrm{MHz}$ radio-frequency (rf)-driven ion sources, designed to fit within a $\sim 5 \mathrm{~cm}$ diameter borehole, is used. Typical operating parameters include repetition rates up to $100 \mathrm{pps}$, with pulse widths between 10 and $80 \mu$ s and source pressures as low as 4 mTorr. In this configuration, peak extractable hydrogen current exceeding $35 \mathrm{~mA}$ from a $2 \mathrm{~mm}$ diameter aperture, together with $\mathrm{H}_{1}^{+}$yields over $94 \%$ have been achieved. The required $\mathrm{rf}$ impedance matching network has been successfully miniaturized to $\sim 5 \mathrm{~cm}$ diameter and tested. Given the low duty cycle operation, the ion source and matching do not require any cooling.
\end{abstract}

\section{INTRODUCTION}

The Ion Beam Technology Program of Lawrence Berkeley National Laboratory (LBNL) is currently developing a compact, rf-driven, pulsed ion source for neutron generation. The motivation for this work is to integrated this neutron generator into an activation analysis instrument for the detection of subsurface pollutants. The details of this application are discussed in another paper in these proceedings (C.M. Celata et al.). LBNL's rf-driven ion sources have found numerous applications ranging from neutral beam injection systems for fusion reactors to particle accelerators, proton therapy machines, and ion implantation systems [1]. Such sources are simple to operate, have long lifetimes, high gas efficiencies and provide high density plasmas with high monatomic species yields. These characteristics make the rf-driven ion source a viable candidate for the next generation of compact, high output, sealed neutron generators. An attempt has been made to miniaturize the rf-driven ion source [2,3] and the necessary impedance matching network to fit in a $5 \mathrm{~cm}$ borehole with the goal of producing $10^{9}$ to $10^{10} \mathrm{D}-\mathrm{T}$ neutrons per second, when coupled to a $100 \mathrm{kV}$ accelerator. Typical operating parameters are: repetition rates of up to 100 pps with pulse widths between 10 and $80 \mu \mathrm{s}$, and source pressures as low as 4 mTorr, which is essential for reducing both charge exchange and highvoltage break-down in the accelerator column. Presently, the repetition rate is limited only by the available rf power supply. The choice of the pulse width stems from the characteristic time (neutron inelastic scattering time) for the activation analysis application. In this configuration, peak hydrogen current densities exceeding $1180 \mathrm{~mA} / \mathrm{cm}^{2}$ with $\mathrm{H}_{1}^{+}$ion species yields over 94\% have been extracted from a 2 -mm-diameter exit aperture. Though all testing was done with hydrogen to minimize radioactive hazards, a similar ion source performance is expected with deuterium.

\section{EXPERIMENTAL SETUP}

The schematic diagram of the ion source is shown in Fig. 1. Three components can be identified as follows. The first is the rf power source which consists of a main $70 \mathrm{~kW}$ (pulse), broad band, rf power amplifier driven at $2 \mathrm{MHz}$ by a signal generator. A pulse generator gates the amplifier so as to generate plasma pulses with durations of up to $80 \mu \mathrm{s}$ and repetition rates up to $100 \mathrm{~Hz}$.

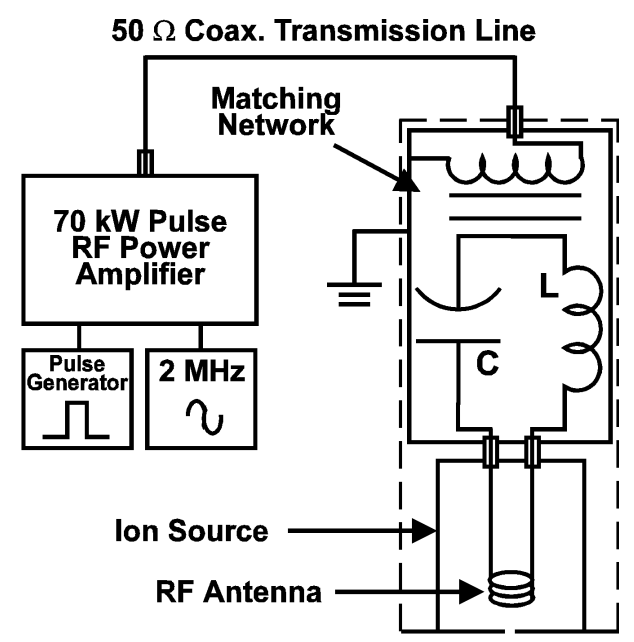

Figure: 1 Schematic of the rf-driven ion source setup.

The next element in the circuit is the impedance matching network. It comprises a 10:1 step-down transformer and an LC tank circuit. The purpose of this network is to match the nominal $50 \Omega$ output impedance of the rf amplifier to the typical low impedance $(\sim 1 \Omega)$ of the plasma-antenna load.

\footnotetext{
* This work is supported by the U.S. Department of Energy under Contract No. DE-AC03-76SF00098
} 
Lastly, to deliver rf energy to the plasma, a coupler in the form of a multi-turn induction coil is used. This $3 \frac{1}{2}$-turn rf induction coil is fabricated from a solid 1.6 $\mathrm{mm}$ diameter copper or stainless-steel wire. This wire is coated with a thin layer of porcelain for electrical insulation from the conducting plasma.

The antenna is immersed in a $2.5 \mathrm{~cm}$ I.D., $8 \mathrm{~cm}$ long copper cylinder. The source is closed-off at one end with a back flange carrying the necessary feedthroughs for the antenna, a gas inlet and a capacitance manometer to monitor source pressure. The extraction system, which closes off the other end of the ion source chamber, contains 2 electrodes with $2 \mathrm{~mm}$ diameter apertures. The first electrode and source body are connected to a $0-25 \mathrm{kV}$, high voltage extraction power supply, while the second electrode is tied to ground. The two electrodes are separated by a gap of $\sim 2$ $\mathrm{mm}$. As dictated by the application, no water cooling is employed, which is possible given the low duty cycle operation $(<0.1 \%)$ limited by the available $\mathrm{rf}$ power amplifier.

Two kinds of beam diagnostics are used to characterize the ion source performance. The first is a Faraday cup to measure the total beam current. The current density is obtained by dividing the extracted current by the aperture area. The second is a magnetic mass spectrometer with which the hydrogen ion species distribution can be determined.

Since the beam is pulsed, a sample-and-hold circuit is used to measure the cup current of the mass spectrometer. To properly suppress any secondary emission electrons, the Faraday cups of both diagnostics are made of graphite and have a pair of permanent magnets embedded at the cup entrance.

\section{EXPERIMENTAL RESULTS}

\subsection{Current Density Measurements}

Because of the difficulty in designing an optimized diode extraction system that can accommodate the broad range of plasma densities for this testing, there were conditions when a fraction of the beam sprayed onto the second electrode. Though this second electrode current to ground can be readily measured, it is difficult to quantify its origin given the variation of the secondary emission coefficient with beam energy and species distribution. As a result, the second electrode current was not measured, making the Faraday cup current a lower bound estimate of the ion source output.

The current density measurements were carried out with the antenna coils centered within the source chamber as well as moved forward, with the tip of the induction coil $0.7 \mathrm{~cm}$ from the first electrode aperture. The rf pulse width was adjusted so that the extracted current pulse length was on the order of $\sim 10 \mu \mathrm{s}$.

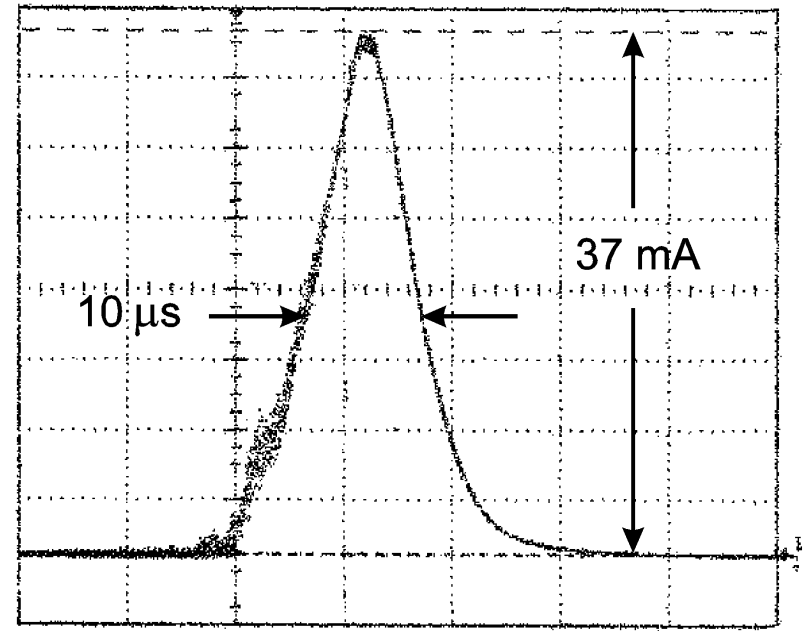

Figure: 2 Typical extracted current pulse shape from a $2 \mathrm{~mm}$ diameter aperture, corresponding to 1180 $\mathrm{mA} / \mathrm{cm}^{2}$ (at $6.2 \mathrm{mTorr}$ and $52 \mathrm{~kW}$ pulse rf input power)

Figure 2 shows the characteristic shape of such short pulses. The beam current pulse taken at the forward antenna position shows a peak value of $37 \mathrm{~mA}$ at $6.2 \mathrm{mTorr}$ source pressure and $52 \mathrm{~kW}$ pulse rf input power. Figures 3 shows the extractable peak current density versus rf input power for three different source pressures. The current density is seen to increase with increasing rf input power. This data was taken with the antenna centered within the source chamber. The extractable current was observed to increase $~ 30-50 \%$ when the antenna was moved forward.

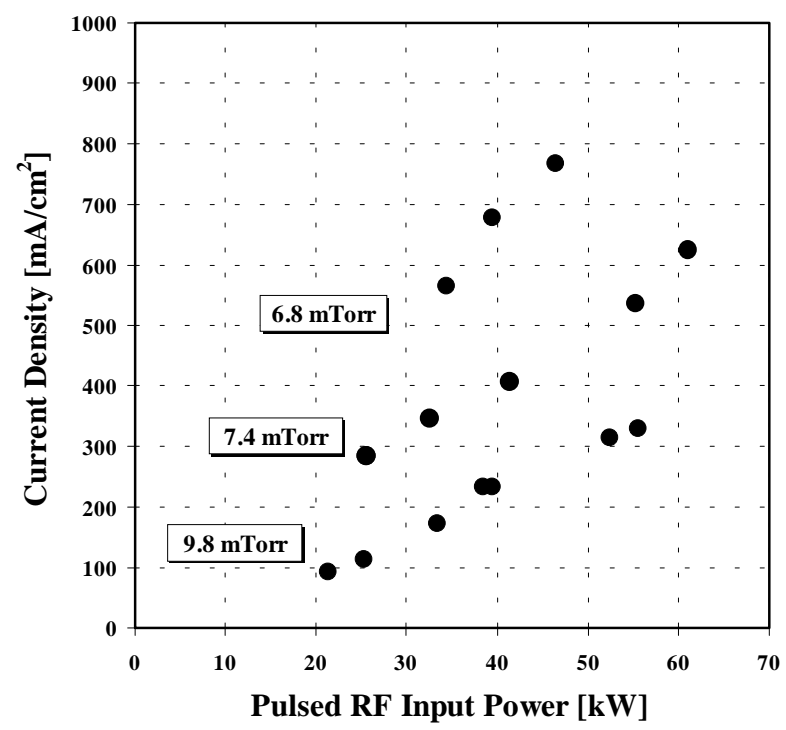

Figure: 3 Peak extractable current density at three different source pressures versus pulse rf input power. Note: $100 \mathrm{~mA} / \mathrm{cm}^{2}$ corresponds to a beam of $3.1 \mathrm{~mA}$ from the $2 \mathrm{~mm}$ diameter aperture. 


\subsection{Hydrogen Ion Species Measurements}

With the rf antenna located at the center of the source, the proton output was found to be in the 60-70\% range, regardless of power and pressure. As the antenna was moved forward, the $\mathrm{H}_{1}^{+}$ion fraction increased to the 8094\% range. Figure 4 shows a characteristic mass spectrum with $\sim 94 \% \mathrm{H}_{1}^{+}$ion yield taken at $60 \mathrm{~kW}$ rf input power and $6 \mathrm{mT}$ Torr of source pressure. Figure 5 shows the hydrogen ion species distribution versus rf power for source pressures ranging from 6 to 9 mTorr. The proton yield is seen to increase with increasing power but is somewhat insensitive to pressure in this range.

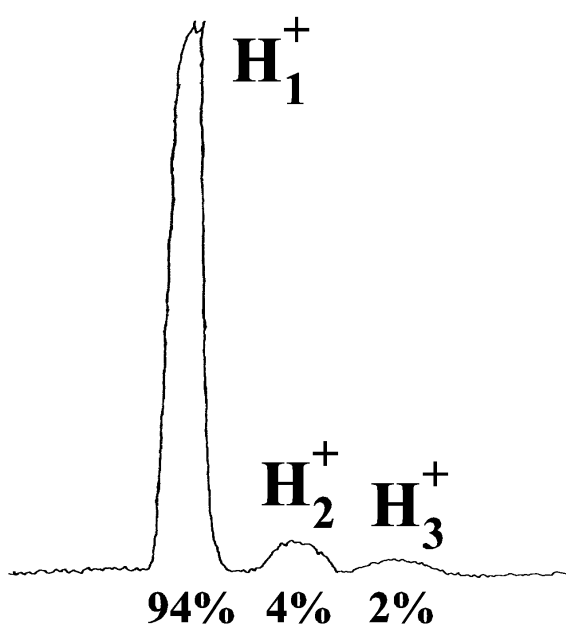

Figure: 4 Hydrogen mass spectrum taken at 5.6 mTorr and $56 \mathrm{~kW}$ pulse rf input power, with the antenna moved forward, near the exit aperture.

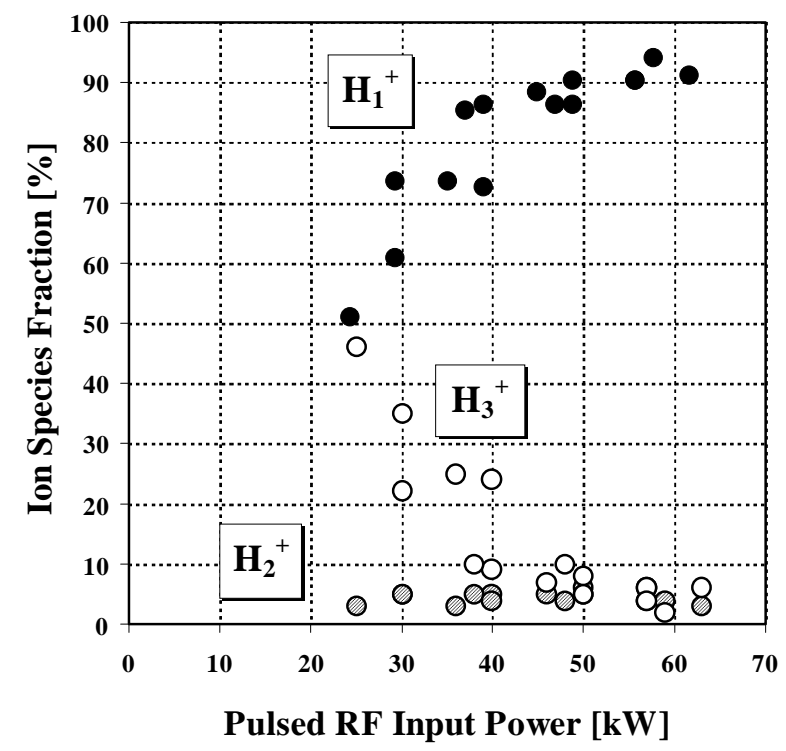

Figure: 5 Hydrogen ion species distribution versus pulse rf input power for pressures in the 6 to $9 \mathrm{mT}$ Torr range, with the antenna moved near the exit aperture

\section{RF IMPEDANCE MATCHING NETWORK}

For the above measurements, a larger sized matching network was employed. A miniature size matching network was also constructed to fit into $\mathrm{a} \sim 5$ $\mathrm{cm}$ diameter borehole. Given the large current on the secondary side of the transformer (up to $300 \mathrm{~A}$ at full power $\left(<\sim 400 \mathrm{~W}_{\text {avg }}\right)$ ), care was taken in the selection of capacitors with low dissipation factors and temperature coefficients. Furthermore, improved electrical wiring (e.g., stranded) and contacts (e.g., silver plated) played a significant role in reducing reduce resistive losses in the secondary circuit. Under full power testing (> $50 \mathrm{~kW})$ and without any active cooling, the drift in the matching network resonant frequency due heating of the capacitors was on the order of $10 \mathrm{kHz} / \mathrm{hr}$ at $0.1 \%$ duty cycle. Further design improvements are being implemented to improve the matching network performance at higher duty factors.

\section{DISCUSSION}

Further experimental details on the development of this compact neutron generator can be found in Ref. [4]. Included in this reference is a detailed estimate of neutron yield assuming a 50\%-50\% D-T discharge, 100 $\mathrm{kV}$ accelerator voltage, and taking into account losses in the accelerator (due to charge exchange). The result of this calculation shows a neutron output of $10^{9} \mathrm{n} / \mathrm{s}$ with 60 $\mu \mathrm{A}$ of average beam current and $80 \%$ monatomic species fraction. With an available duty factor of $0.1 \%$ at 100 $\mathrm{Hz}$, this average current corresponds to $60 \mathrm{~mA} /$ pulse. The ion source output is expected to be sufficient to achieve at least $10^{9} \mathrm{D}-\mathrm{T}$ neutrons per second with a larger $3 \mathrm{~mm}$ beam aperture accelerator design. Without cooling considerations, a neutron yields in excess of $10^{10}$ $\mathrm{n} / \mathrm{s}$ can be expected with a further increase in beam aperture and/or increase in the repetition rate of the $\mathrm{rf}$ amplifier.

\section{ACKNOWLEDGEMENTS}

We would like to thank, G. J. DeVries, R. Keller, W. B. Kunkel, M. Rickard, and S. Wilde for their technical assistance. This work is supported by the U.S. Department of Energy under Contract No. DE-AC0376 SF00098.

\section{REFERENCES}

[1] Leung, K. N., Rev. Sci. Instrum., 67, 1302, 1996.

[2] Perkins, L. T., Herz, P. R, Leung, K. N, and Pickard, D. S., Rev. Sci. Instrum., 65, 1186, 1994.

[3] Perkins, L. T., DeVries, G. J., Herz, P. R., Kunkel, W. B., Leung, K. N., Pickard, D. S., Wengrow, A., and Williams, M. D., Rev. Sci. Instrum., 67, 1057, 1996.

[4] L. T. Perkins et al., Proceedings of the $14^{\text {th }}$ ICAARI, Denton, TX, Nov. 6-9, 1996 